\title{
Penyempurnaan Penulisan Skripsi
}

\author{
Ismail Suardi Wekke
}




\title{
Kompetensi dasar
}

\author{
Menulis Akademik
}

2

Publikasi ilmiah, dari Skripsi ke Artikèl 


\section{INDIKATOR PEMBELAJARAN}
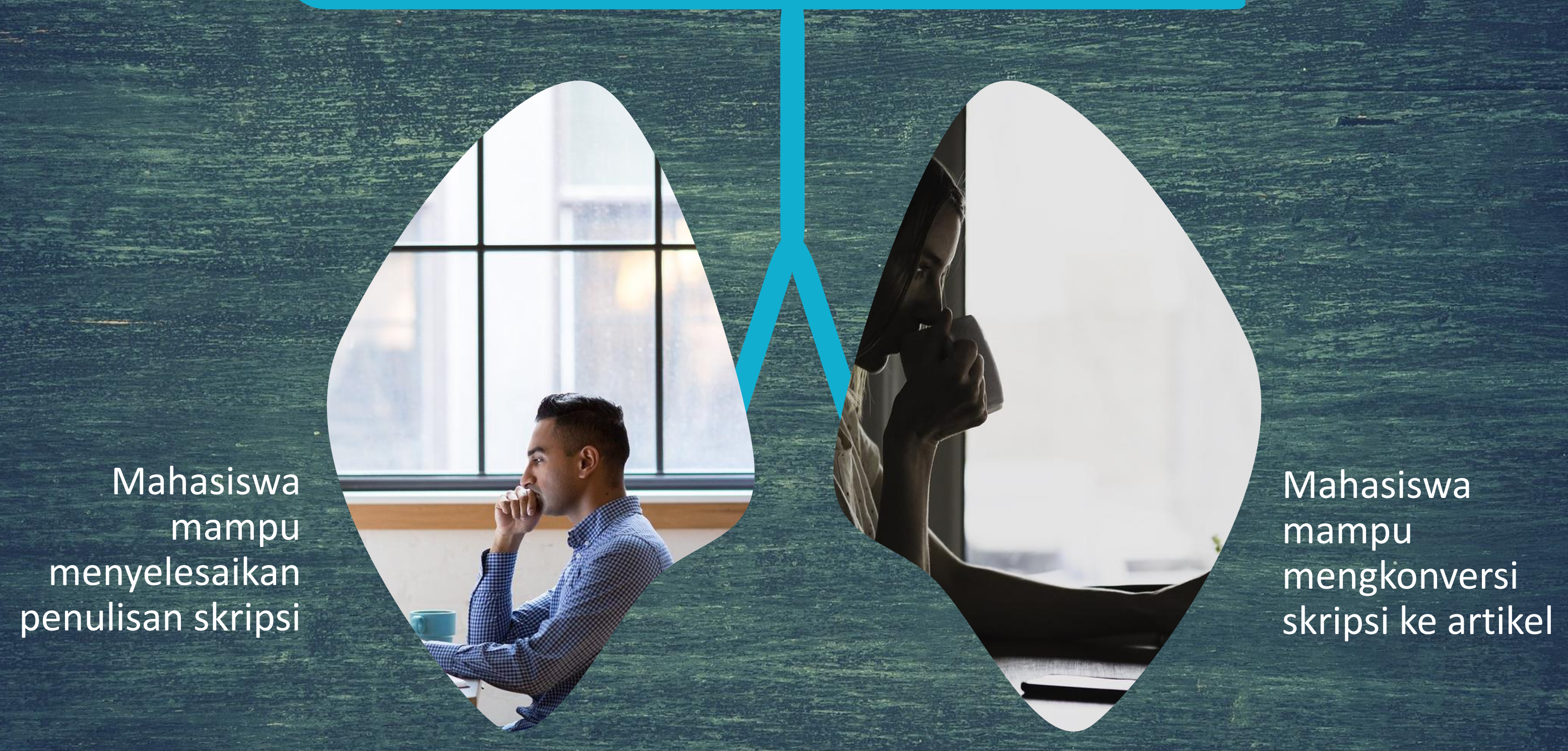


\section{POIN BAHASAN}

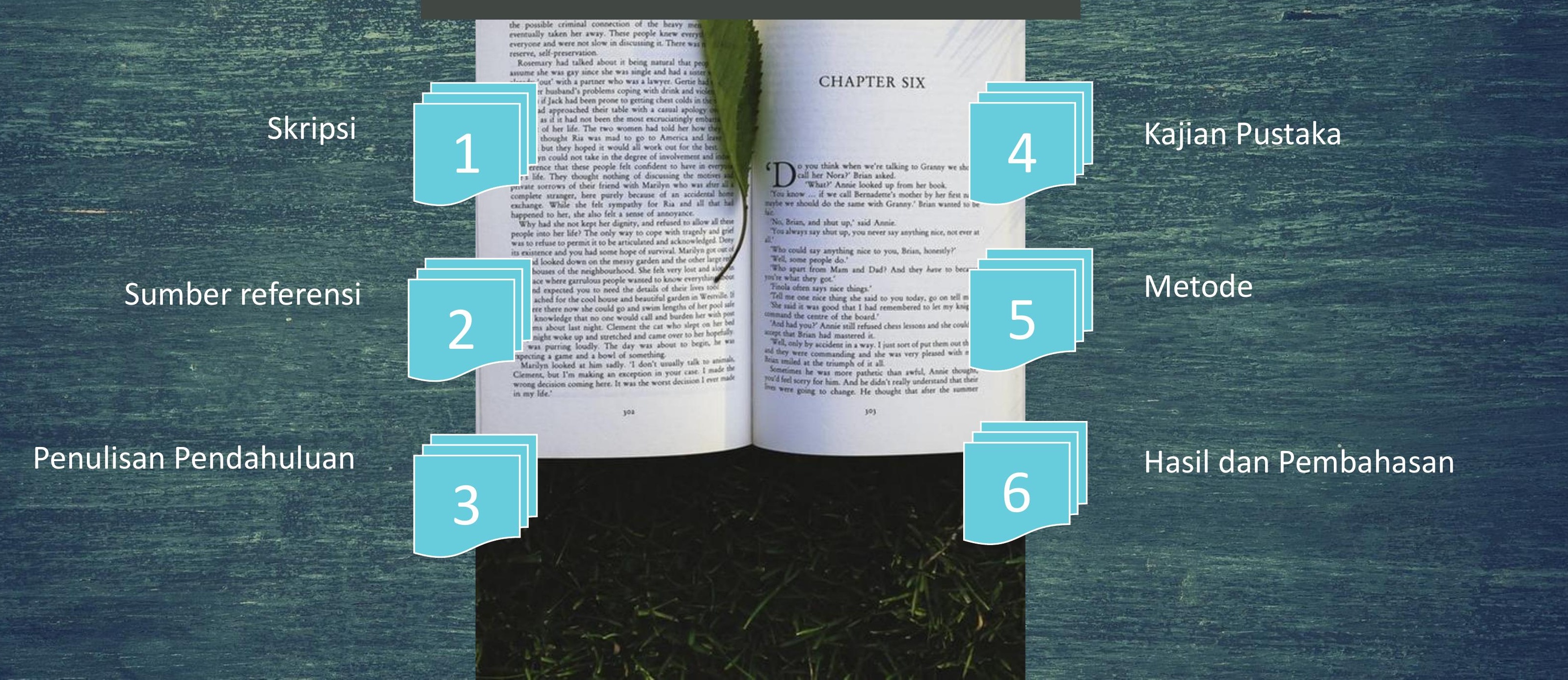




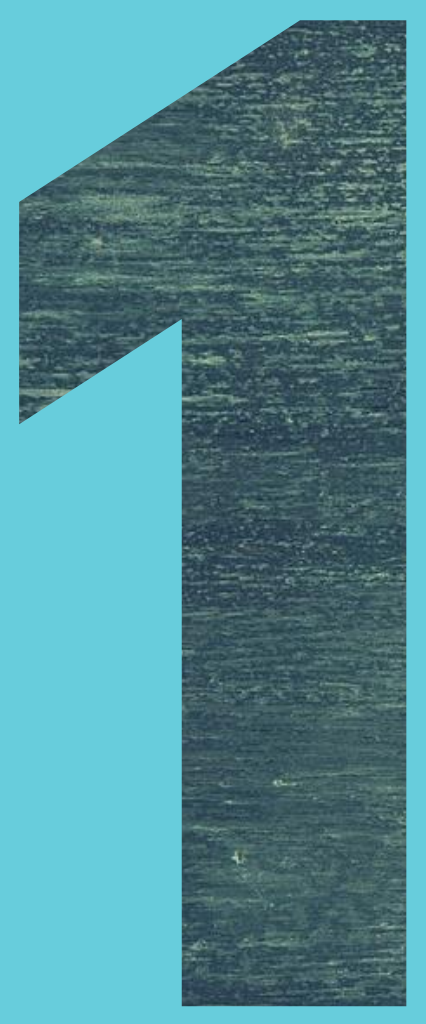

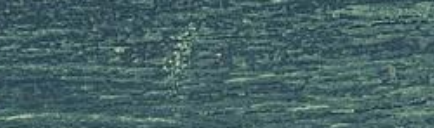

$+7$

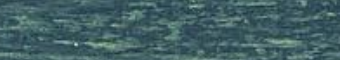

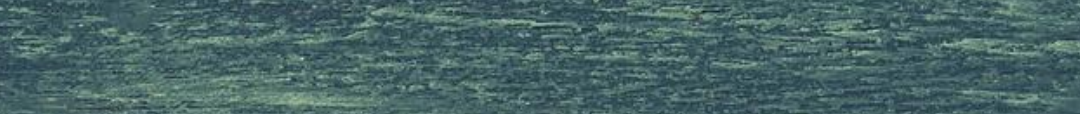

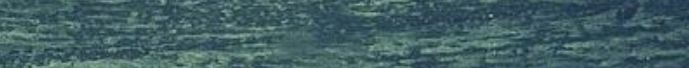

SKRIPSI 


\section{Skripsi Sebagai Matakuliah}

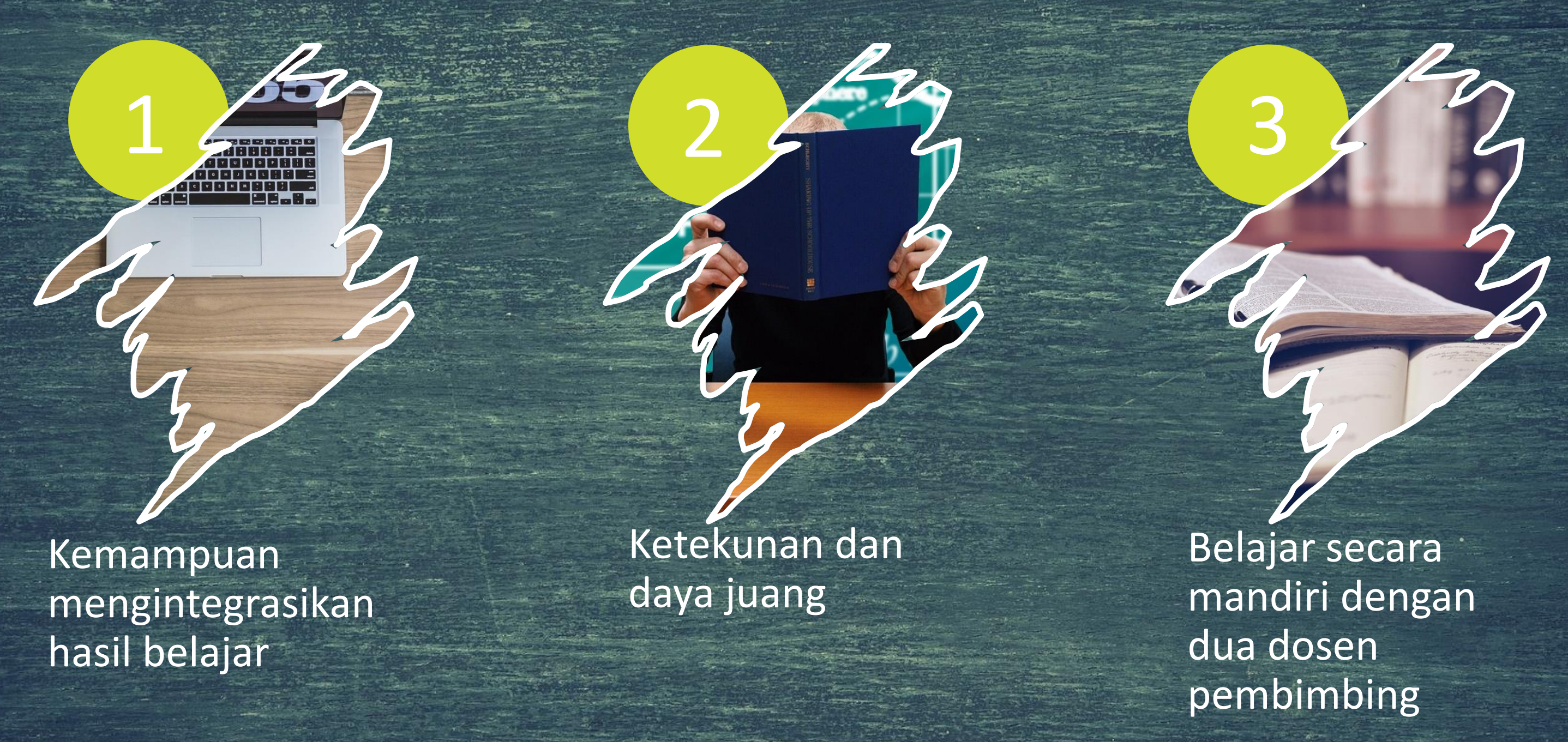




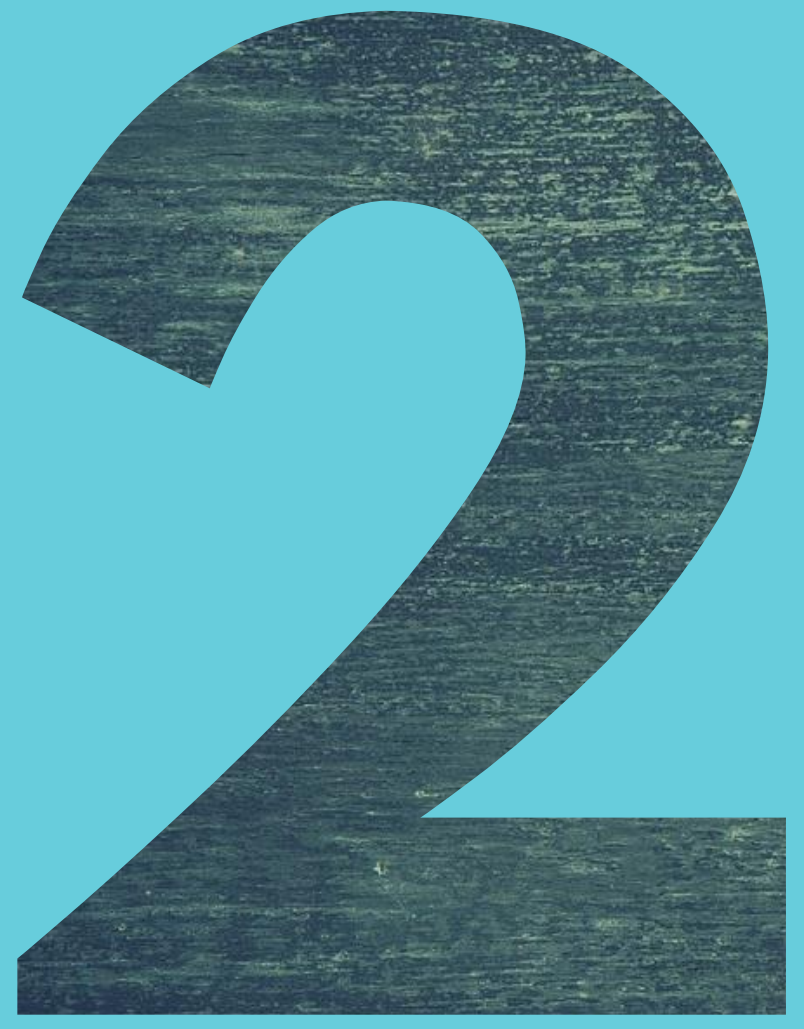

SUMBER REFERENSI 


\section{PANGKALAN DATA}

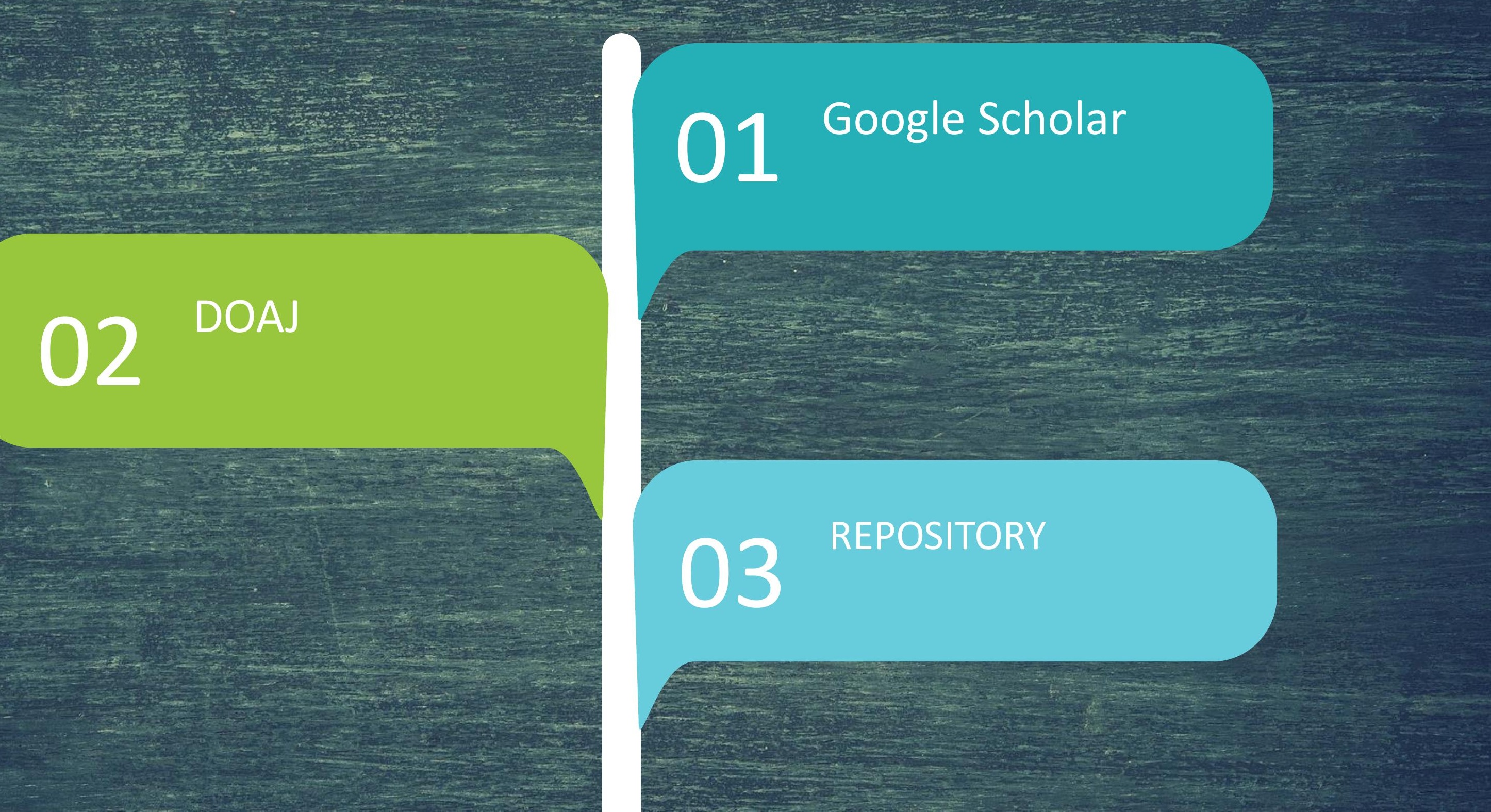




\section{KRITERIA}
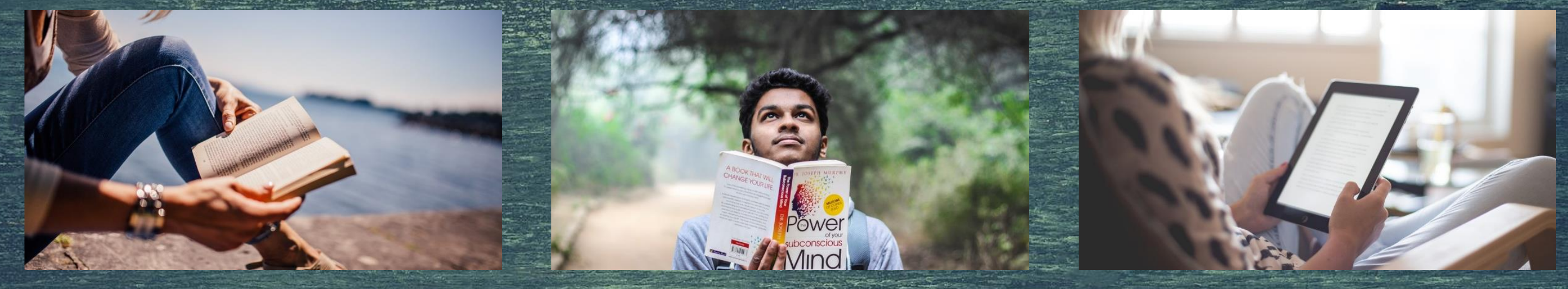

MUTAKHIR

PRIMER

TERSEDIA DARING 


\section{Penulisan}

\section{PENDAHULUAN}




\section{EMPAT TAHAPAN}

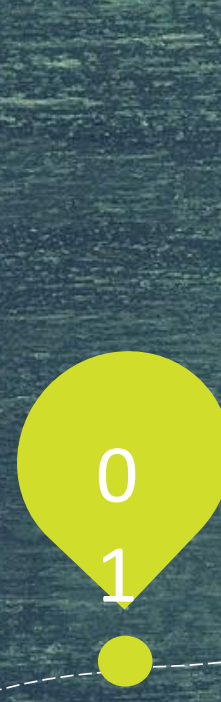

02

Perbedaan dengan publikasi sebelumnya

Kenapa penting?

Apa yang sudah ada? 


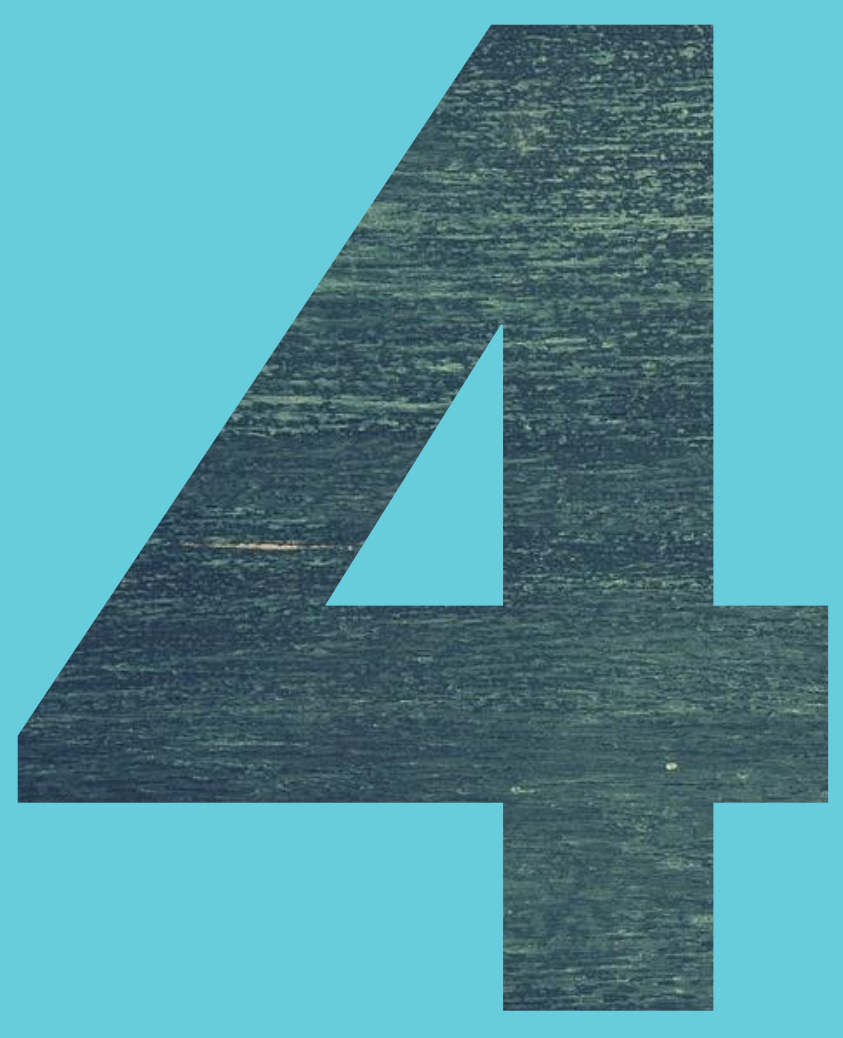

\section{KAJIAN PUSTAKA}




\section{Alat Bantu (tools)}

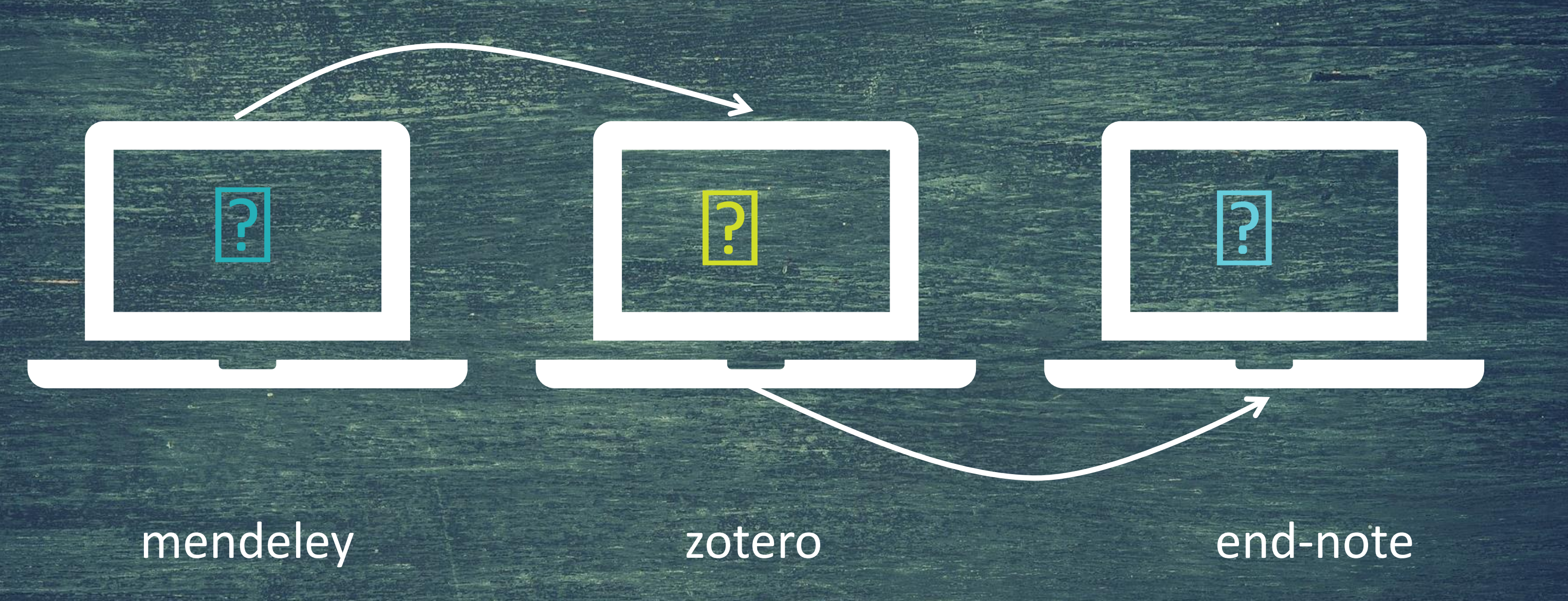




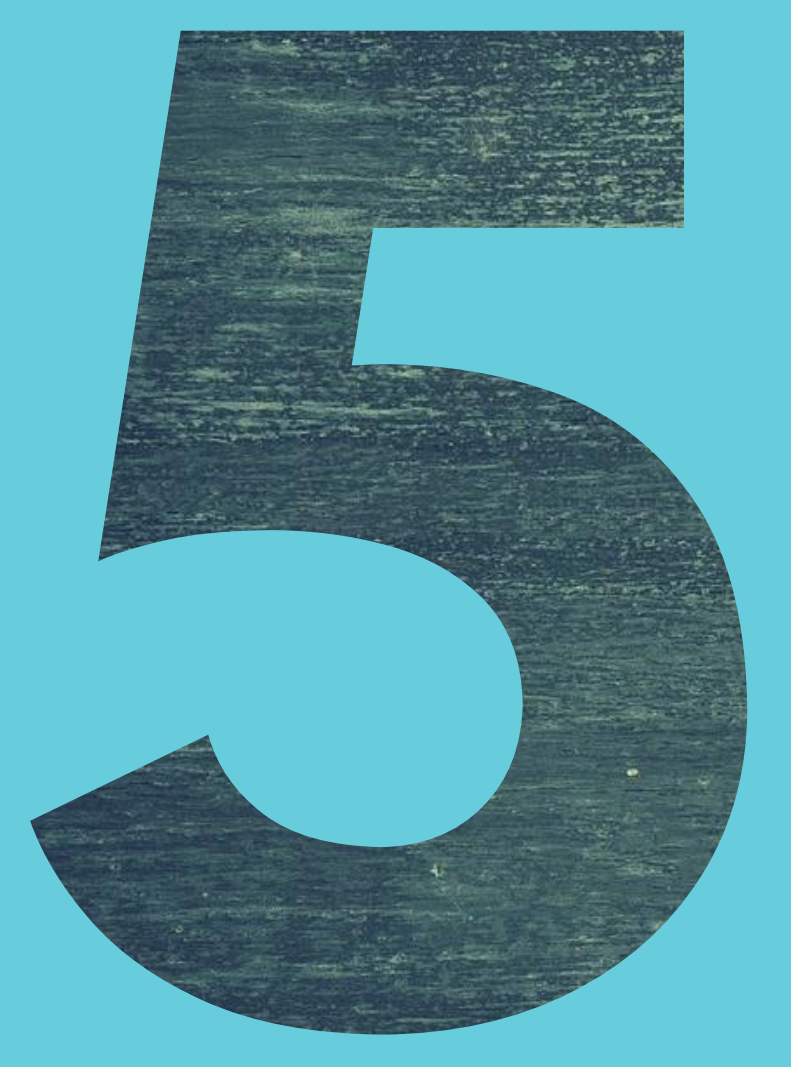

$$
\text { METODE }
$$

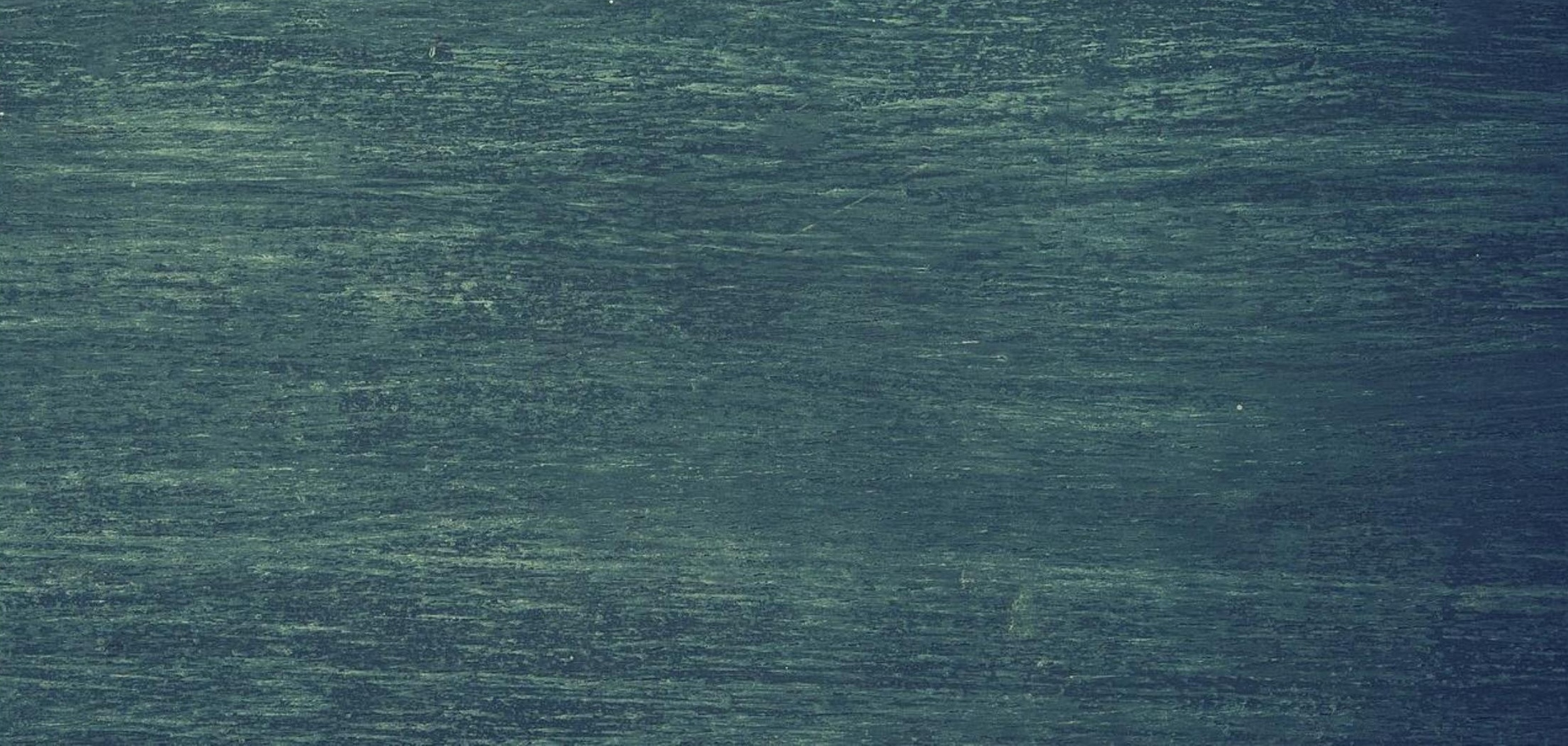




\section{KELENGKAPAN}

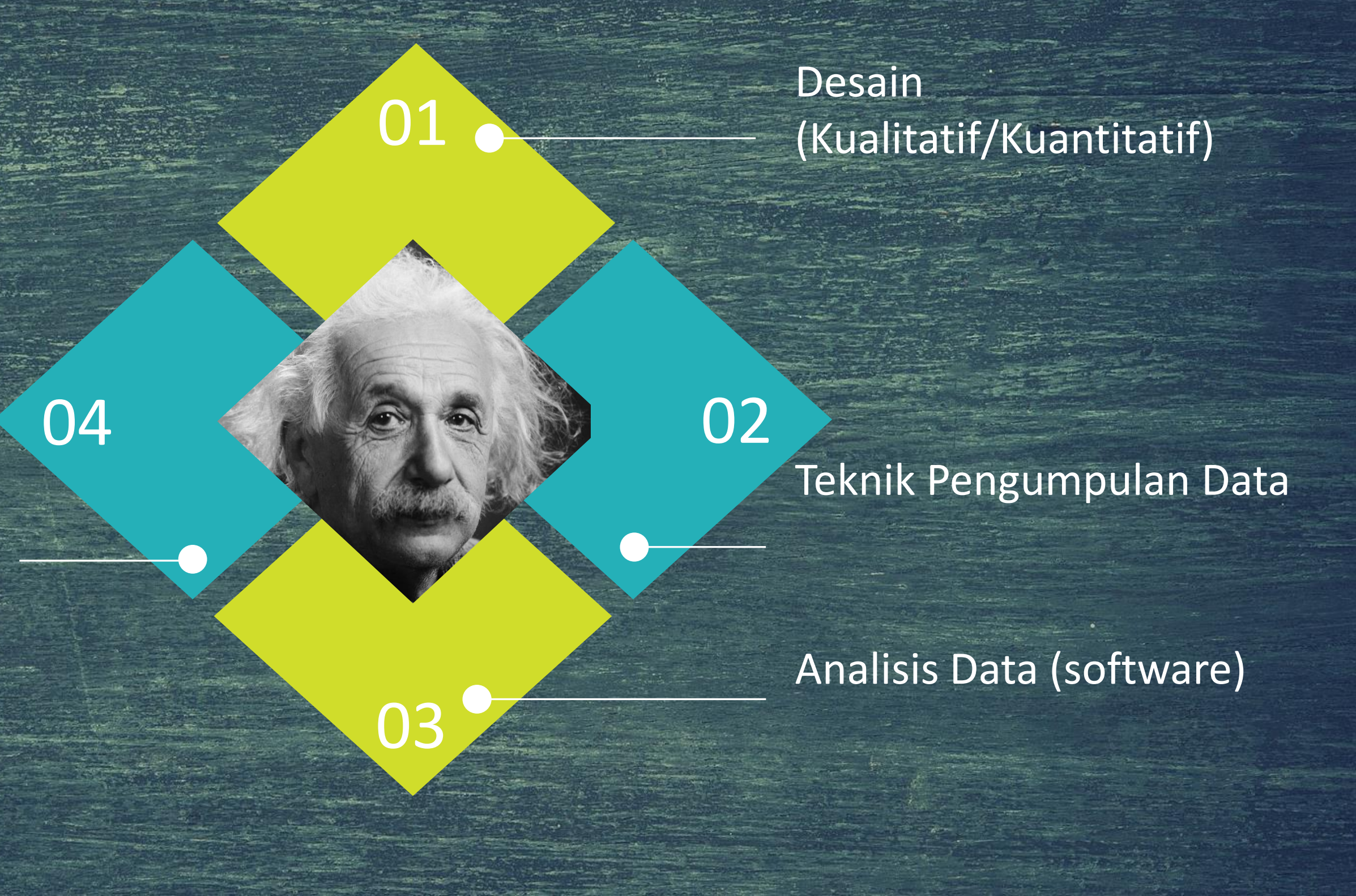




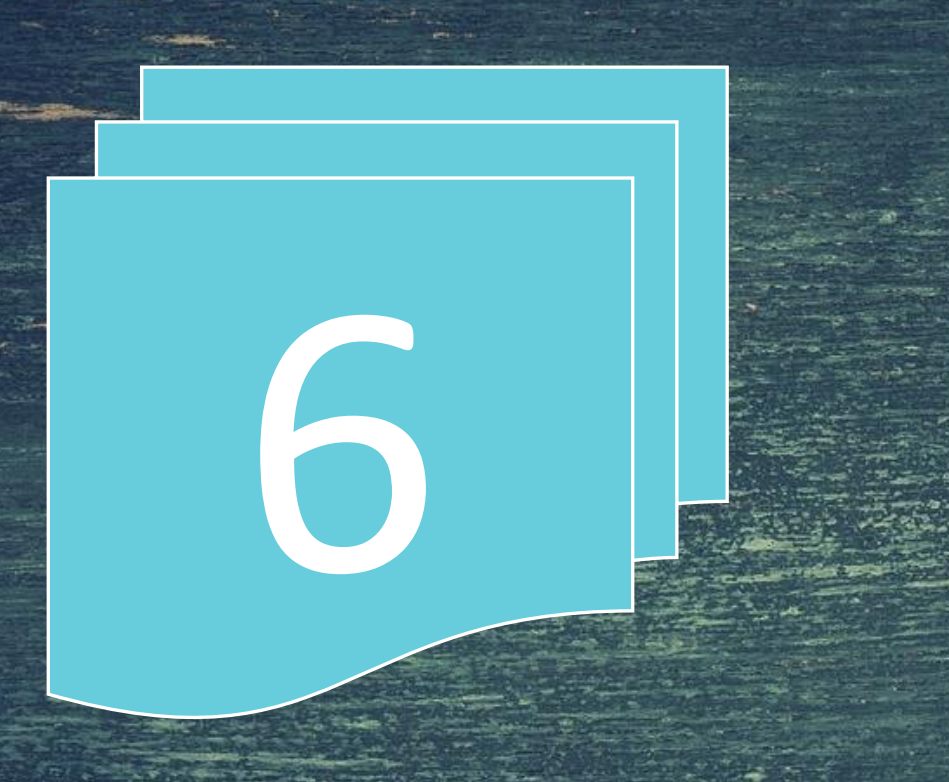

Hasil \& Pembahasan

01 Tunjukkan hasil sebagai jawaban pertanyaan

02 Kemukakan apa adanya

03 Hasil yang sudah dianalisis

04 Kemukakan hasil dalam bentuk pembahasan

05 Apa temuan utama? 


\section{Konversi Skripsi ke Publikasi}

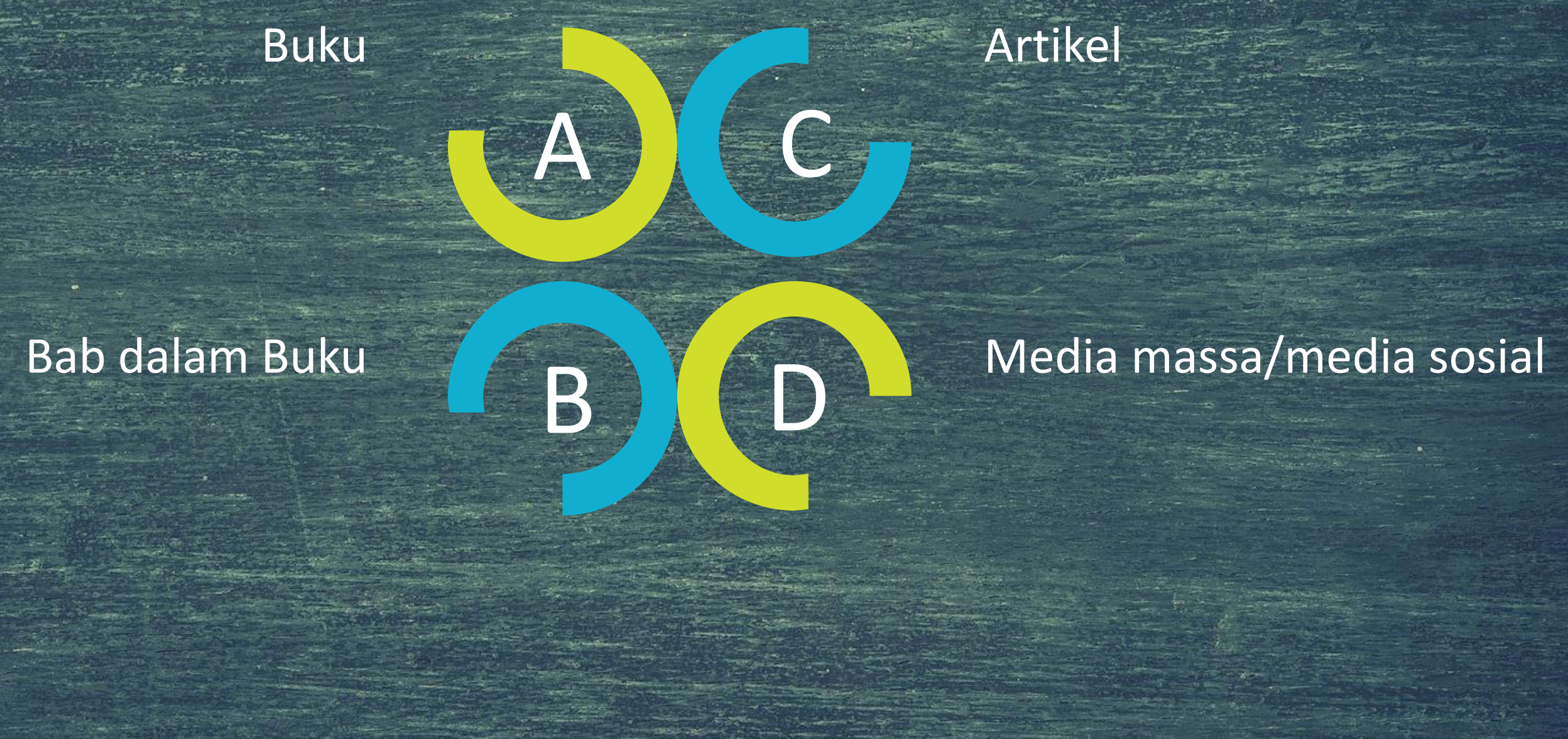




\section{PUBLIKASI ARTIKEL}

02 Topik Pendidikan dalam pelbagai aspek

MISTAR:
Jurnal Pendidikan

(3) Terbit 2 kali

setahun 


\section{MISTAR: \\ Jurnal Pendidikan}

http://journal.insanakademis.id/index.php/mistar/index 


\section{Terima Kasih}

